\title{
A novel production route and process optimization of biomass- derived paraffin wax for pharmaceutical application
}

\author{
Hannes Gruber ${ }^{\text {a, b, * }}$, Lukas Lindner ${ }^{\mathrm{a}, \mathrm{b}}$, Stefan Arlt ${ }^{\mathrm{b}}$, Alexander Reichhold ${ }^{\mathrm{a}}$, \\ Reinhard Rauch ${ }^{\text {b, }}$, Gerald Weber ${ }^{\text {b, }}{ }^{* *}$, Jürgen Trimbach ${ }^{d}$, Hermann Hofbauer ${ }^{\text {a }}$ \\ anstitute of Chemical, Environmental \& Bioscience Engineering, TU Wien, Vienna, Austria \\ ${ }^{\mathrm{b}}$ BEST Bioenergy and Sustainable Technologies GmbH, Vienna, Austria \\ ${ }^{c}$ Engler-Bunte-Institute, Karlsruhe Institute of Technology, Karlsruhe, Germany \\ ${ }^{\mathrm{d}} \mathrm{H} \& \mathrm{R} \mathrm{GmbH} \& \mathrm{Co}$. KGaA, Hamburg, Germany
}

Keywords:

Renewable paraffin wax

Fischer-tropsch synthesis (FTS)

Hydrofining

Process optimization

\begin{abstract}
A B S T R A C T
The Biomass to Liquid (BtL) Fischer Tropsch (FT) route converts lignocellulosic feedstock to renewable hydrocarbons. This, paper shows a novel production route for biomass derived synthetic paraffin wax via gasification of lignocellulosic feedstock, Fischer Tropsch synthesis (FTS) and hydrofining. The Fischer Tropsch wax was fractionated, refined and analyzed with respect to compliance to commercial stan dards. The fractioned paraffin waxes were hydrofined using a commercial sulfide NiMo $\mathrm{Al}_{2} \mathrm{O}_{3}$ catalyst and a trickle bed reactor. A parametric variation was performed to optimize the hydrofining process. It was shown that the produced medium melt paraffin wax could fulfill the requirements for "Paraffinum solidum" defined by the European Pharmacopoeia (Ph. Eur). The high melt wax fraction showed po tential to be used as food packaging additive. Furthermore, the renewable wax was analyzed regarding $\mathrm{PAH}$ content and it was shown that the hydrofined wax was quasi PAH free.
\end{abstract}

\section{Introduction}

Crude oil and natural gas are important feedstocks for the chemical industry. The International Energy Agency (OECD/IEA, 2018) published that in 2017 the chemical and petrochemical in dustry accounted for about $14 \%$ and $8 \%$ of the primary oil and natural gas demand, respectively. Future scenarios also reported by IEA predict an increasing demand for primary chemicals. Thus, if no shift towards renewable technologies will be undertaken, the fossil energy consumption of the chemical and petrochemical industry is going to rise equally. In contrast, it is going to be necessary to reach and uphold net zero anthropogenic $\mathrm{CO}_{2}$ emissions in this century to

\footnotetext{
* Corresponding author. Institute of Chemical, Environmental \& Biological Engineering, TU Wien, Vienna, Austria.

** Corresponding author. BEST Bioenergy and Sustainable Technologies GmbH, Vienna, Austria.

E-mail addresses: hannes.gruber@tuwien.ac.at (H. Gruber), stefan.arlt@bestresearch.eu (S. Arlt), alexander.reichhold@tuwien.ac.at (A. Reichhold), reinhard. rauch@kit.edu (R. Rauch), gerald.weber@best-research.eu (G. Weber), Juergen. Trimbach@hur.com (J. Trimbach), hermann.hofbauer@tuwien.ac.at (H. Hofbauer).
}

limit global warming to levels below $2{ }^{\circ} \mathrm{C}$ above pre industrial levels (Masson Delmotte et al., 2018). To achieve the ambitious goal to limit global warming to $1.5{ }^{\circ} \mathrm{C} \mathrm{CO}_{2}$ emissions need to be reduced by approximately $45 \%$ by 2030 (United Nations, 2019). Whether the $1.5^{\circ} \mathrm{C}$ or the $2{ }^{\circ} \mathrm{C}$ goal is considered, energy consuming sectors need to substitute fossil with renewable feedstock. The chemical and petrochemical industry faces a dilemma in this regard. In this sector hydrocarbons are consumed as fuel and synthesis component. The synthesis of renewable hydrocarbons via BtL FT (Rauch et al., 2013) might be a key technology to provide renewable hydrocarbon as feed for this industry. Furthermore, the use of FTS has the potential to enable the utilization of greenhouse gas $\mathrm{CO}_{2}$ (Bahri et al., 2019), and the utilization of excess electricity from renewable sources (Eilers, 2018) to benefit the reduction of anthropogenic $\mathrm{CO}_{2}$ emissions even more.

Wax is generally understood as consistency term (Deutsche Gesellschaft für Fettwissenschaften, 1975) and the fossil pathway to obtain paraffin wax is a well known process, described by Krendlinger et al. and Speight (Krendlinger et al., 2015; Speight, 2011). In a first step, slack wax is obtained by solvent dewaxing of vacuum distillates via cooling and filtration. Fig. 1 shows an 


\begin{tabular}{|ll|}
\hline \multicolumn{2}{|l|}{ List of abbreviations } \\
FT & Fischer Tropsch \\
FTS & Fischer Tropsch synthesis \\
BtL & Biomass to Liquid \\
PAH & Poly aromatic hydrocarbon \\
Ph. Eur & European Pharmacopoeia \\
FDA & Food and Drug Administration \\
SBCR & Slurry Bubble Column Reactor \\
LTFT & Low temperature Fischer Tropsch synthesis \\
LHSV & Liquid hourly space velocity \\
LoD & Limit of determination \\
BTX & Benzene, toluene, xylene \\
NH & Ammonia \\
HCl & Hydrogen chloride \\
DFB & Dual fluidized bed \\
$\mathrm{C}_{\mathrm{i}}$ & Hydrocarbons with i carbon atoms \\
EU & European Union \\
US & United States \\
CO & Carbon monoxide \\
$\mathrm{H}_{2}$ & Hydrogen \\
\hline
\end{tabular}

industrial vacuum rotary filter that is used for this process. The slack wax obtained from filtration is subsequently separated from residual solvent, fractioned and refined to white paraffin wax. Thus, the production capacity of fossil paraffin wax is strongly linked to lubricant production and in general to crude oil refining. On the contrary, Low Temperature Fischer Tropsch synthesis (LTFT) en ables the production of paraffin wax independently from cure oil refining. The LTFT raw syncrude contains over $40 \mathrm{wt} \%$ of paraffin waxes $\left(\mathrm{C}_{20+}\right)$ (de Klerk and Maitlis, 2013). Beside the usage as feedstock for fuel production via hydrocracking, FT raw wax can be refined to specialty wax (Steynberg, 2004). The catalytic upgrading of wax was reviewed by de Klerk and Furimsky (de Klerk and Furimsky, 2010a). Specialty waxes are important raw materials, which are used to produce and improve the performance of commodities like hot melts (Kalish et al., 2015; Paul, 2003), rubber products (Agrawal et al., 2005), candles, bitumen (Leng et al., 2017; Wen et al., 2018) and pharmaceutical and cosmetic products. Each application re quires different physical and chemical wax properties. Rough es timations regarding the marked potential of waxes were summarized and published by Krendlinger et al. (2015). Market prices of over 1200 EUR per ton for medium melt and high melt

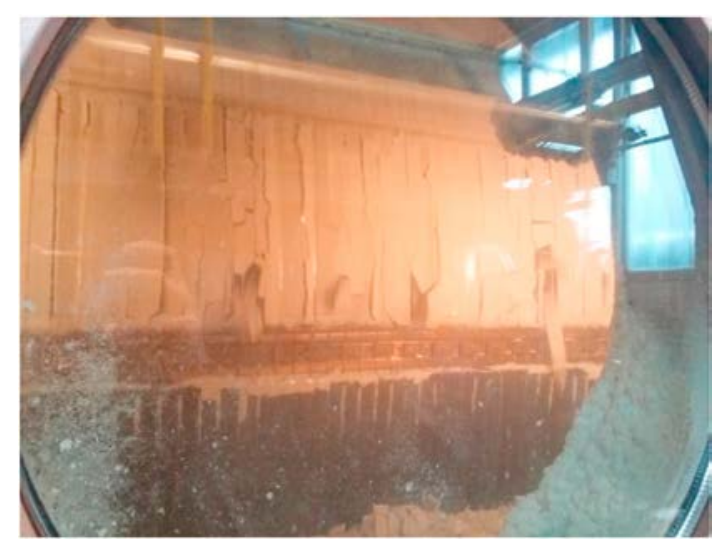

Fig. 1. Industrial dewaxing process removal of slack wax from the vacuum-rotary filter. wax are currently obtainable in EU and US markets.

Bolder (2007) investigated the hydrofining of high melt paraf finic FT waxes, which were produced in a commercial fixed bed reactor using an iron based catalyst. However, there is a lack of literature regarding the refining process of FT medium melt waxes for highly regulated pharmaceutical applications. This study was conceptualized to investigate the production of renewable paraf finic medium melt FT wax for pharmaceutical application (Ph. Eur monography for "Paraffinum solidum"). Additionally, a high melt FT wax was refined and tested to FDA criteria for "Paraffin (syn thetic) (21CRF175.250)". The FT waxes used in this study were produced in a laboratory slurry FT reactor using a pre commercial cobalt catalyst.

\section{Material and methods}

In this work, raw paraffinic FT wax obtained from gasification of lignocellulosic feedstock and cobalt based LTFT was separated via distillation into a medium and high melt fraction. Both waxes were hydrofined using a laboratory scale hydrotreating unit.

\subsection{Production of renewable Fischer Tropsch paraffin wax}

The raw paraffinic FT waxes used in this investigation were pro duced via gasification and LTFT. Fig. 2 shows the basic flow sheet of the applied process chain, which consist of a commercial biomass gasification plant and a laboratory scale FT unit. The commercial 8 $\mathrm{MW}_{\text {th }}$ biomass gasification plant provided the raw product gas for the hydrocarbon production. The steam blown dual fluidized bed (DFB) gasifier converted wood chips to $\mathrm{H}_{2}$ and $\mathrm{CO}$ rich product gas (Bolhàr Nordenkampf and Hofbauer, 2004). The main fraction of the product gas was used to produce heat and power on a commercial scale. A small fraction of the product gas was used for FTS. The provided product gas was subsequently dried and contaminants (BTX, $\mathrm{NH}_{3}, \mathrm{HCl}$ and sulfur components) were removed. Acceptable levels regarding syngas impurities (Boerrigter et al., 2002; Rauch et al., 2013) were achieved using an extended gas cleaning sec tion. In the applied laboratory setup, the product gas components $\mathrm{CO}_{2}$ and $\mathrm{CH}_{4}$, both non convertible by cobalt based FTS, were kept in the gas stream. However, in industrial plants non syngas components would be removed or converted to syngas with a gas loop (Dry and Steynberg, 2004).

Cobalt based LTFT typically produces a wax fraction with a high share of paraffins (equation (1)) and a low share of olefins (equation (2)) and oxygenates (e.g. alcohols equation (3)) (Dalai and Davis, 2008; de Klerk and Furimsky, 2010b).

$$
\begin{array}{ll}
(2 n+1) \mathrm{H}_{2}+n \mathrm{CO} \rightarrow \mathrm{C}_{n} \mathrm{H}_{2 n+2}+n \mathrm{H}_{2} \mathrm{O} & \text { equation } 1 \\
(2 n) \mathrm{H}_{2}+n \mathrm{CO} \rightarrow \mathrm{C}_{n} \mathrm{H}_{2 n}+n \mathrm{H}_{2} \mathrm{O} & \text { equation } 2 \\
(2 n) \mathrm{H}_{2}+n \mathrm{CO} \rightarrow \mathrm{C}_{n} \mathrm{H}_{2 n+1} \mathrm{OH}+\left(\begin{array}{ll}
n & 1
\end{array}\right) \mathrm{H}_{2} \mathrm{O} & \text { equation 3 }
\end{array}
$$

The characteristics of the applied 20 L slurry bubble column reactor (SBCR) were described by Ripfel Nitsche (2017). A detailed summary of the FT experiments, which produced the raw paraffin wax used as feedstock for hydrofining, was published by Gruber et al. (2019). The SBCR was operated at 20 bar and $230^{\circ} \mathrm{C}$ and a pre commercial cobalt catalyst was applied. CO conversions of up to $52 \%$ per reactor pass were obtained. Fig. 3 shows a typical composition of the condensed FT syncrude produced by the applied setup. About 45 to $50 \mathrm{wt} \%$ of the total FT product were hydrocarbons with 20 and more carbon atoms. After product condensation, a wiped film evaporator and a short path evaporator were used to separate the FT wax into two frac tions. The two renewable FT wax batches, a medium melt wax 


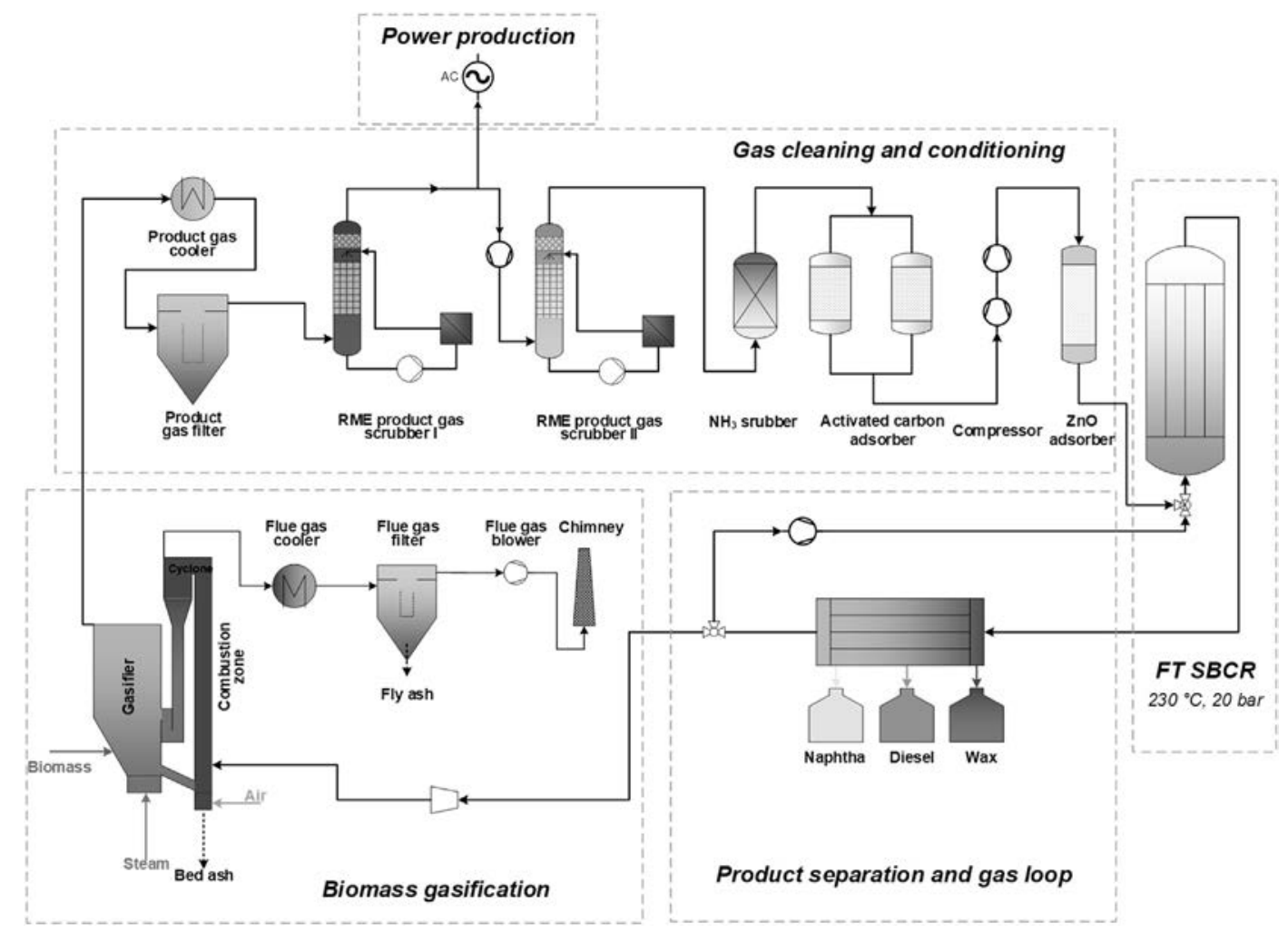

Fig. 2. Basic flow sheet of renewable hydrocarbon production.

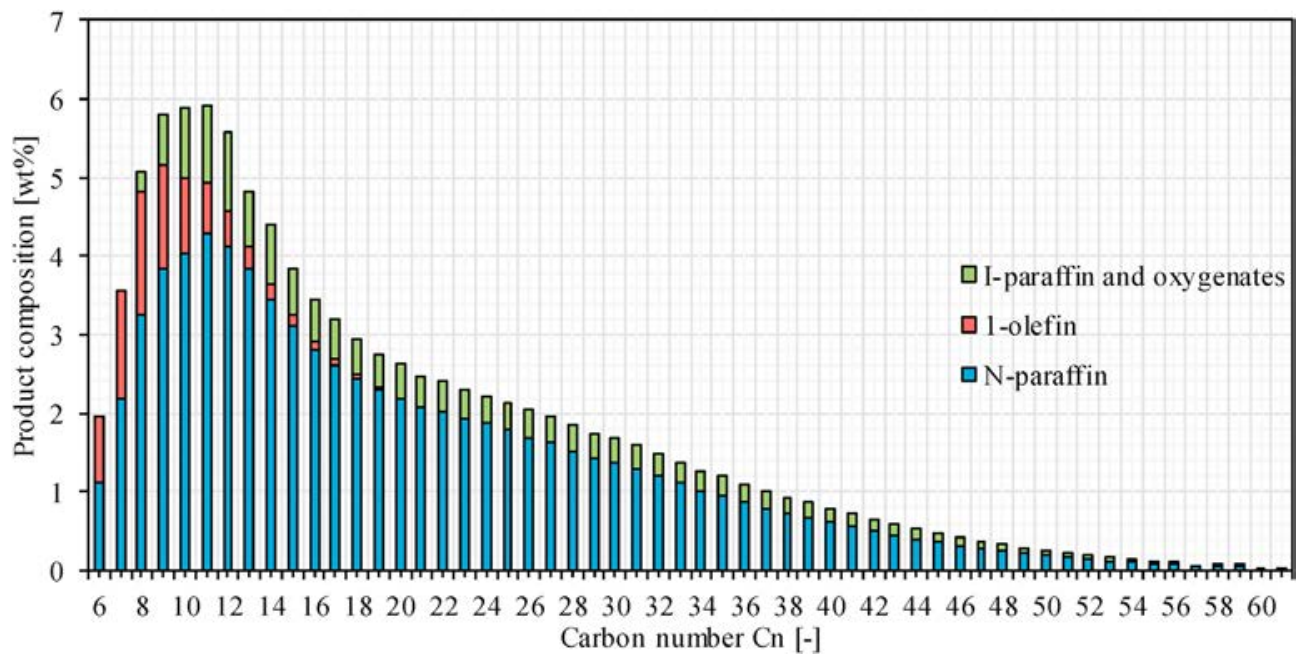

Fig. 3. Exemplary product composition of condensed FT syncrude.

"Wax A" and a high melt wax "Wax B" were used as feedstock for further refining. Based on the total FT product, about $35 \mathrm{wt} \%$ medium melt wax and about $15 \mathrm{wt} \%$ high melt wax could be obtained. The boiling range of these wax batches were chosen to comply with thermal properties required for synthetic paraffin according to FDA and Ph. Eur. standards.

\subsection{Fischer Tropsch wax characterization}

The renewable FT paraffin wax was characterized by standards developed for fossil based equivalents. Table 1 shows important parameters that were evaluated before and after the wax hydrofining. Changes of these parameters after the hydrofining step indicate physical and chemical modifications to wax.

Table 1

Paraffin wax characterization methods.

\begin{tabular}{lll}
\hline Characteristic & Unit & Standard \\
\hline Congealing point & {$\left[{ }^{\circ} \mathrm{C}\right]$} & DIN ISO 2207 \\
Needle penetration & {$\left[10^{1} \mathrm{~mm}\right]$} & DIN EN 1426 \\
Boiling range distribution & {$[-]$} & DIN EN 15199 \\
N-paraffin content & {$[w \mathrm{wt} \%]$} & GC-in-house \\
Oil content & {$[\mathrm{wt} . \%]$} & DIN 51531 \\
\hline
\end{tabular}


The hydrofining performance was evaluated with respect to the wax color improvement and changes to physical and chemical properties. Two methods were used to describe the paraffin color. A fast and reliable wax characterization regarding color quality is the Saybolt Color, which is used to grade slightly yellowish to whitish hydrocarbons. The Saybolt Color was determined according to ASTM D156 using a Hach Lange LICO 500 colorimeter. The Saybolt Color scale ranges from 16 (slightly colored) to +30 (quasi colorless). Additionally, the hot acid test, an in house method, was applied to analyze the wax regarding polar coloring impurities. This method is more sensitive regarding coloring impurities than the Saybolt Color. The hot acid test was performed by mixing hot wax with $\mathrm{H}_{2} \mathrm{SO}_{4}$. Two phases, an acidic phase and a wax phase were obtained. The grading scale of the hot acid test ranges from 1 to 3 . Grade 1 means no coloring and grade 3 strong coloring of the acidic phase. Grade 1 and 2 are acceptable for industrial medium melt waxes. Fig. 4 shows the reference sample for grade 1 and grade 2 compared to a FT paraffin wax sample (grade 1-2). This method could not be applied to qualify Wax B due to its high boiling range.

Moreover, the refined renewable FT waxes were tested regarding their compliance with commercial standards. Table 2 lists tested parameters and the corresponding standards. Wax A was analyzed regarding the $\mathrm{Ph}$. Eur. criteria fulfillment for "Paraffinum solidum". The FDA standard "175.250 Paraffin (synthetic)" was consulted to investigate the applicability of Wax B as indirect food additives.

Table 3 shows physical and chemical properties of Wax A and B. Both waxes had a n paraffin content $>65 \mathrm{wt} \%$. The high melt wax had a very small oil content with $<1 \mathrm{wt} \%$. The oil content of the softer medium melt wax was $<6$ wt\%. Fig. 5 and Fig. 6 show the raw waxes and their associated hydrocarbon distribution. Raw Wax A had a slightly yellowish appearance, with a Saybolt Color of +15 and a hot acid test grade +3 . The $C_{\max }$ was determined at $C_{31}$ and over $95 \mathrm{wt} \%$ of the hydrocarbons were in the range from $C_{20}$ to $C_{40}$. Raw Wax B had a yellowish/brownish appearance, which corre sponds to a Saybolt Color of $<16$. The $C_{\max }$ was determined at $C_{41}$

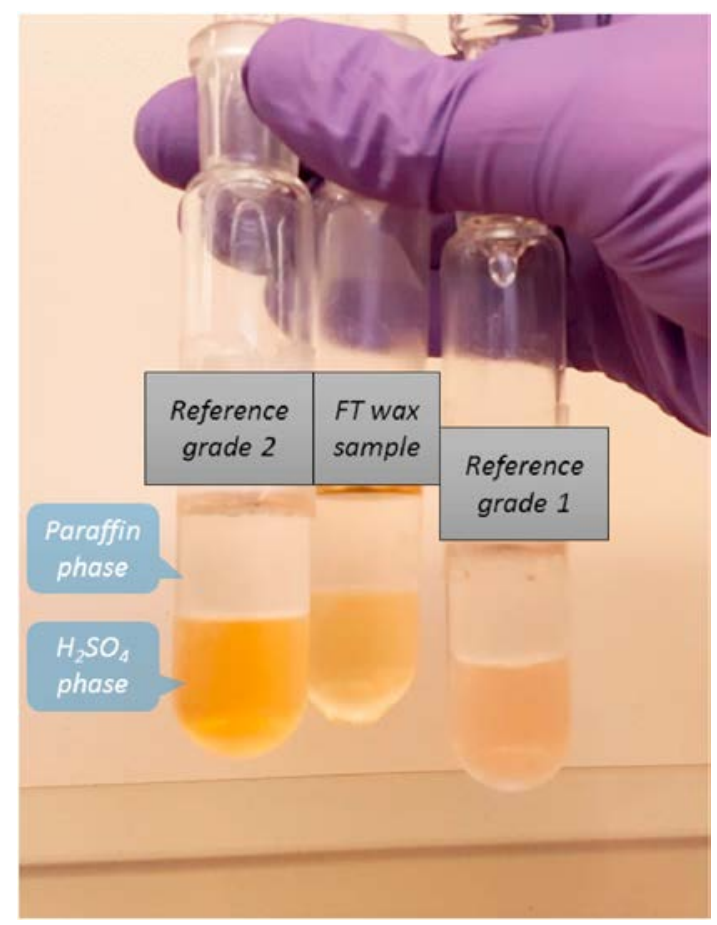

Fig. 4. FT paraffin compared to reference hot acid grades.
Table 2

Criteria for commercial paraffin wax applications.

\begin{tabular}{lll}
\hline Characteristic & Standard & Wax \\
\hline IR spectroscopy & Ph. Eur & Wax A \\
Acidic/base characteristic & Ph. Eur & Wax A \\
PAH & Ph. Eur/GC-MS & Wax A \\
Sulfate & Ph. Eur & Wax A \\
Absorption in decalin & FDA & Wax B \\
Congealing point & FDA & Wax B \\
Oil content & FDA & Wax B \\
\hline
\end{tabular}

and over $96 \mathrm{wt} \%$ of molecules had more than 35 carbons atoms.

All analyses were performed according to the associated stan dard. Except the in house methods for carbon number distribution, substance class analysis and hot acid test the repeatability of the applied methods were reviewed by interlaboratory tests.

\subsection{Hydrofining of paraffinic Fischer Tropsch wax}

Fig. 7 shows the hydrofining unit used to perform the experi ments. This unit enabled hydroprocessing at pressures of up to 200 bar, temperatures up to $400{ }^{\circ} \mathrm{C}$ and a wax flowrate of $1-1000 \mathrm{ml} \mathrm{h}$. The feed vessel was pressurized with $\mathrm{N}_{2}$. Raw waxes were liquefied at temperatures above $100{ }^{\circ} \mathrm{C}$. A high precision piston pump fed the wax into the trickle bed hydrofining reactor. Additionally, $\mathrm{H}_{2}$ was fed at the desired pressure into the hydro fining reactor. A detailed scheme of the once through $500 \mathrm{ml}$ trickle bed reactor is shown in Fig. 8. The liquefied wax and the $\mathrm{H}_{2}$ flowed downwards through the reactor. The support material distributed the wax homogenously throughout the reactor profile and acted as a layer of protection, retaining solid impurities. The product ejec tion was controlled automatically by an optical sensor, which in dicates the liquid level of the collection vessel and opens at a given set point. The refined wax was collected and cooled in product vessels.

The hydrofining experiments were performed with a commer cial sulfide $\mathrm{Ni} / \mathrm{Mo}-\mathrm{Al}_{2} \mathrm{O}_{3}$ catalyst. The catalyst was mixed with sand in a ratio of $1: 1$ by volume to obtain a more homogenous temper ature profile. During the hydrofining process a sulfurous compo nent was added to the wax feed to maintain the sulfide state of the catalyst.

Two parametric variations and a long term test run were per formed to evaluate the hydrofining performance of the $\mathrm{Ni}$ / $\mathrm{Mo}-\mathrm{Al}_{2} \mathrm{O}_{3}$ catalyst on FT waxes. Table 4 shows the experiments performed with Wax $A$. The $\mathrm{H}_{2}$ to wax ratio (equation (4)) was kept between 741 and 760 .

$\mathrm{H}_{2 / \text { wax }}$ ratio $\dot{V}_{\mathrm{H}_{2} / \dot{V}_{\text {wax }}}$

equation 4

The liquid hourly space velocity (LHSV) (equation (5)) was var ied between 0.5 and $0.75 \mathrm{~h}^{-1}$. In order to evaluate the effect of temperature and pressure these parameters were varied from 260 to $280{ }^{\circ} \mathrm{C}$ and 140 to 35 bar, respectively. Additionally, a $96 \mathrm{~h}$ long term test run was performed with Wax $A$ at commercial near hydrofining conditions.

LHSV $\quad \dot{V}_{\text {wax }} / V_{\text {catalyst }}$

equation 5

Table 5 shows the experiments performed with Wax B. The hydrofining temperature was varied from 280 to $340{ }^{\circ} \mathrm{C}$ and pres sure levels of 100 and 140 bar were investigated. The LHSV and the $\mathrm{H}_{2}$ to wax ratio were kept constant. 
Table 3

Wax properties after thermal separation and before hydrofining.

\begin{tabular}{|c|c|c|c|c|c|c|c|}
\hline Wax & Saybolt Color & Hot acid test & Congealing point & Needle penetration & Oil content & $\mathrm{N}$-paraffin content & $C_{\max }$ \\
\hline & {$[-]$} & {$[-]$} & {$\left[{ }^{\circ} \mathrm{C}\right]$} & {$\left[10^{1} \mathrm{~mm}\right]$} & [wt.\%] & [wt.\%] & {$[-]$} \\
\hline Raw Wax A & 15 & $>3$ & 58 & 52 & 5.84 & 70.9 & 31 \\
\hline Raw Wax B & $<-16$ & 1 & 85 & 9 & 0.97 & 66.77 & 41 \\
\hline
\end{tabular}
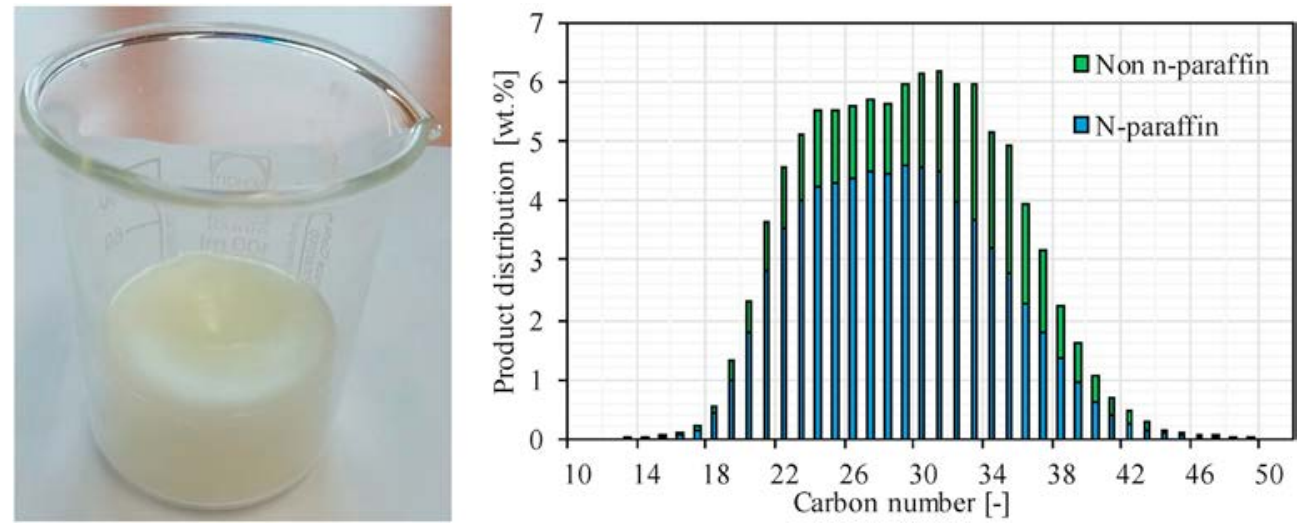

Fig. 5. Medium-melt Wax A after thermal separation; left solid wax, right chromatogram.
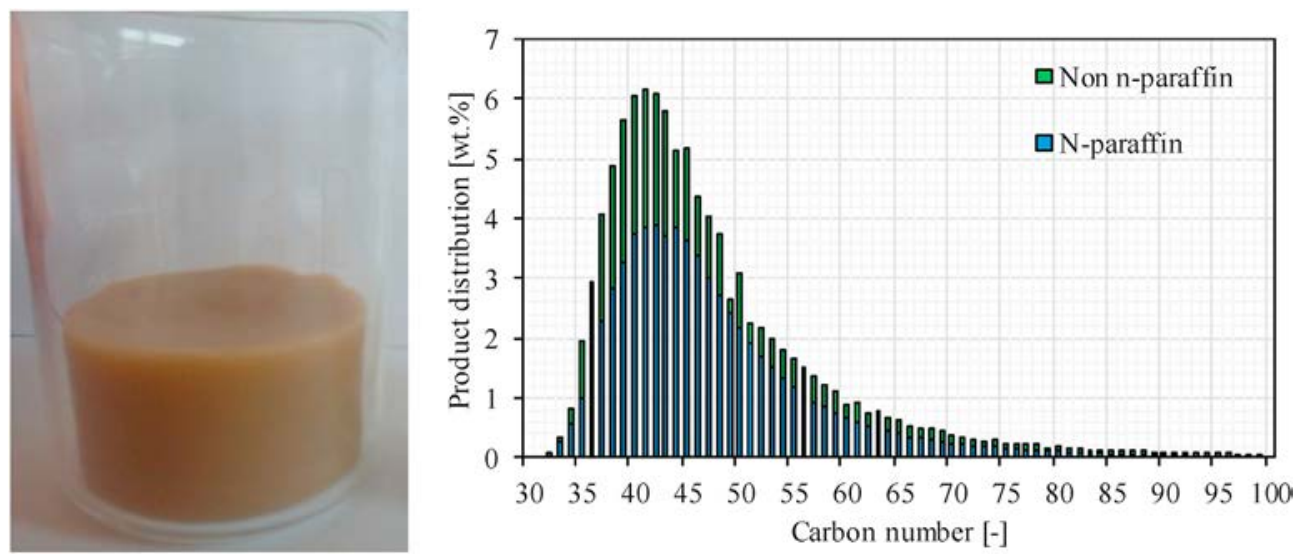

Fig. 6. High-melt Wax B after thermal separation; left solid wax, right chromatogram.

\section{Results}

Table 6 shows the results of the parameter variation performed with Wax A. Experiment HFA 1 achieved maximum color quality attested by Saybolt Color +30 and a hot acid grade 1 . The pressure could be reduced to 35 bar (HFA 4) before a slight decline in wax quality, indicated by an increased hot acid grade, was observed. The temperature reduction to $260{ }^{\circ} \mathrm{C}$, performed in HFA 5, showed a distinct coloration of the acidic phase. An increase of the LHSV by $50 \%$ to $0.75 \mathrm{~h}^{-1}$ (HFA 6) showed still excellent results regarding color quality. Thus, $280^{\circ} \mathrm{C}$ and 60 bar might be the lower threshold to obtain a maximum color quality for Wax A. Tests regarding oil content, congealing point, needle penetration and SIMDIST showed stable results throughout the parameter variation.

Fig. 9 shows the carbon number distribution and the share of $n$ paraffin of the hydrofined wax HFA 2 and HFA 6. Compared to the raw Wax $A$, the hydrofined wax samples showed a slight decrease regarding $n$ paraffin content and a slight increase in $C_{\max }$. The GC analysis showed that HFA 2 had a n paraffin content of $66.5 \mathrm{wt} \%$ and $95.7 \mathrm{wt} \%$ of the hydrocarbons were in the range of $\mathrm{C}_{20}$ to $\mathrm{C}_{40}$ showing a $C_{\max }$ at $C_{33}$. The sample obtained at increased SV and lower pressure (HFA 6) had a $n$ paraffin content of $67.1 \mathrm{wt} \%$ and $95.6 \mathrm{wt} \%$ of the hydrocarbons were in the range of $C_{20}$ to $C_{40}$. The $\mathrm{C}_{\max }$ of HFA 6 was determined at $\mathrm{C}_{29}$.

Fig. 10 shows the results of the long term hydrofining test run performed at $280^{\circ} \mathrm{C}, 100 \mathrm{bar}, 0.5 \mathrm{~h}^{-1}$ and with a $\mathrm{H}_{2}$ to wax ratio of 750. Properties of the raw Wax $A$ are represented at zero hours experiment duration. Throughout the long term experiment the commercial NiMo- $\mathrm{Al}_{2} \mathrm{O}_{3}$ catalyst showed stable hydrofining per formance. The results obtained matched the ones from the short term experiment under equal conditions (HFA 2) within the margin of error. Again, an increase in Saybolt Color to +30 was achieved and no significant changes on the congealing point, nee dle penetration and oil content could be observed.

The wax samples HFA 4, HFA 5 and HFA 6 were tested with respect to compliance with the Ph. Eur. regarding the requirements defined in the monograph "Paraffinum Solidum". All hydrofined samples met the requirements regarding basicity/acidity, melting 


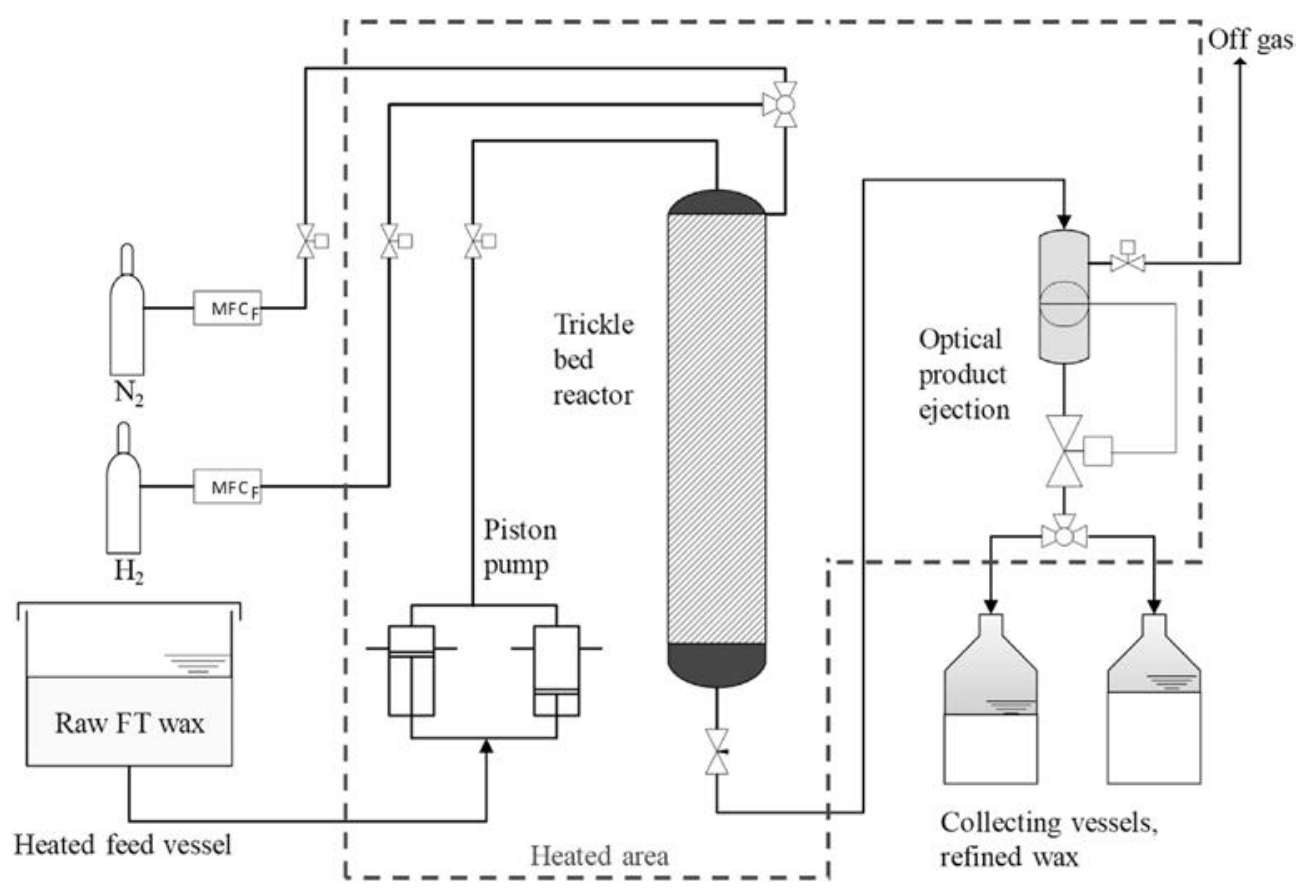

Fig. 7. Flowsheet of hydrofining unit.
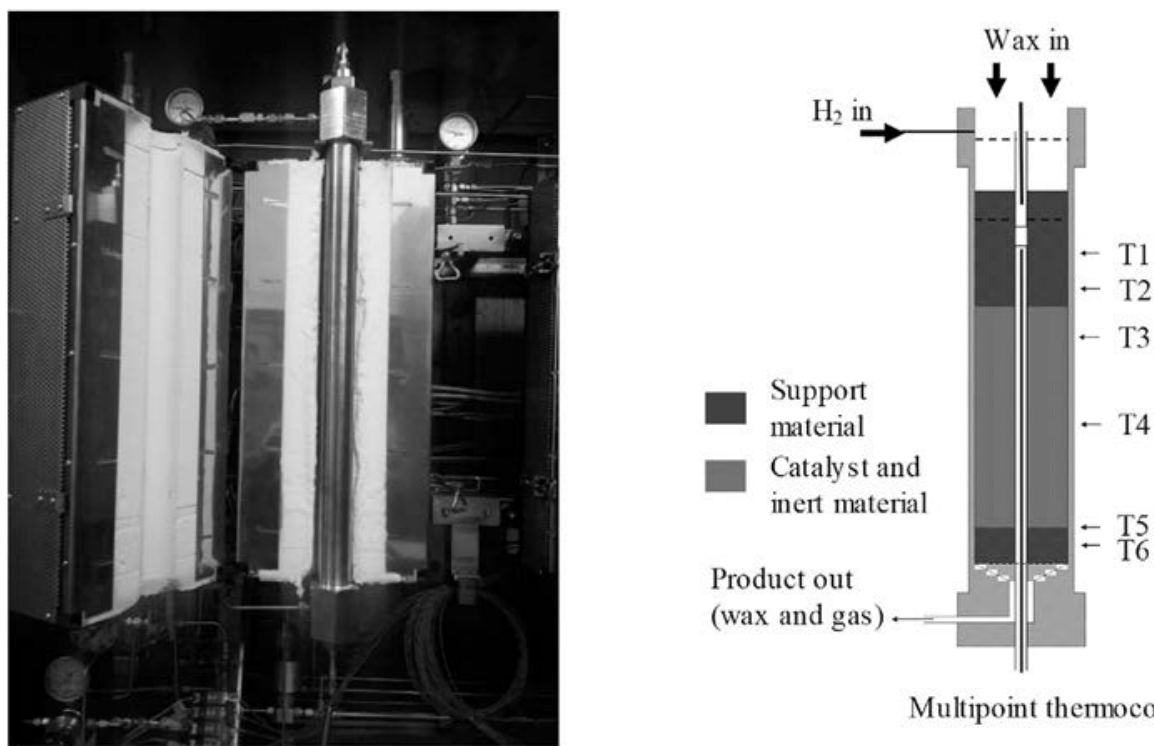

Multipoint thermocouple

Fig. 8. Scheme of the trickle bed hydrofining reactor

temperature, sulfate and $\mathrm{PAH}$. The test regarding infrared identity was performed using a fossil based reference sample that complies with the according requirements. Fig. 11 shows the IR spectrum of the raw Wax A and the hydrofined wax HFA 6 compared to the reference spectrum. The raw Wax A shows deviation compared to the reference spectrum. HFA 6 shows an identical spectrum compared to the reference sample.

The results of the parameter variation performed with Wax B are shown in Fig. 12 to Fig. 14. Fig. 12 shows the color improvement and a slight decline regarding congealing point if temperature was increased. Compared to the raw Wax B (Saybolt Color $<16$ ), an obvious color enhancement could be obtained by hydrofining at 140 bar and $280{ }^{\circ} \mathrm{C}$ (Saybolt Color +18 ). A Saybolt Color of +28 could be obtained by increasing the hydrofining temperature to $340{ }^{\circ} \mathrm{C}$. The decreased congealing point at hydrofining tempera tures above $300{ }^{\circ} \mathrm{C}$ indicated the beginning of cracking. The com plementary analysis regarding oil content, needle penetration (Fig. 13) and boiling curve (Fig. 14) also indicated minor cracking at temperatures $>280{ }^{\circ} \mathrm{C}$. The pressure reduction from 140 to 100 bar at $300^{\circ} \mathrm{C}$ performed at experiment HFB 5 showed a decline in Saybolt Color from 26 to 23.

Fig. 15 shows the GC analysis of HFB 4. The compound analysis showed a $n$ paraffin content of $63.6 \mathrm{wt} \%$ and a $C_{\max }$ at $C_{41}$. Compared to the raw Wax $\mathrm{B}$ the $\mathrm{n}$ paraffin content decreased by $3 \mathrm{wt} \%$ and the $\mathrm{C}_{\max }$ stayed at $\mathrm{C}_{41}$. Furthermore, the analysis showed that $95.2 \mathrm{wt} \%$ of the hydrocarbons had a carbon number $>\mathrm{C}_{35}$. 
Table 4

Experimental plan Wax A

\begin{tabular}{|c|c|c|c|c|c|}
\hline Experiment & Pressure & Temperature & LHSV & $\mathrm{H}_{2}$ :wax & Duration \\
\hline & [bar] & {$\left[{ }^{\circ} \mathrm{C}\right]$} & {$[1 / \mathrm{h}]$} & {$\left[\mathrm{l}_{\mathrm{H} 2} / \mathrm{l}_{\mathrm{wax}}\right]$} & {$[\mathrm{h}]$} \\
\hline HFA-1 & 140 & 280 & 0.5 & 750 & 28.5 \\
\hline HFA-2 & 100 & 280 & 0.5 & 750 & 24.5 \\
\hline HFA-3 & 60 & 280 & 0.5 & 750 & 29 \\
\hline HFA-4 & 35 & 280 & 0.5 & 750 & 38 \\
\hline HFA-5 & 60 & 260 & 0.5 & 750 & 37 \\
\hline HFA-6 & 60 & 280 & 0.75 & 741 & 30 \\
\hline \multicolumn{6}{|c|}{ long-term test run } \\
\hline HFA-7 & 100 & 280 & 0.5 & 750 & 22 \\
\hline HFA-8 & 100 & 280 & 0.5 & 750 & 24 \\
\hline HFA-9 & 100 & 280 & 0.5 & 750 & 24 \\
\hline HFA-10 & 100 & 280 & 0.5 & 750 & 26 \\
\hline
\end{tabular}

Table 5

Experimental plan Wax B.

\begin{tabular}{|c|c|c|c|c|c|}
\hline Experiment & Pressure & Temperature & LHSV & $\mathrm{H}_{2}$ :wax & Duration \\
\hline & [bar] & {$\left[{ }^{\circ} \mathrm{C}\right]$} & {$[1 / \mathrm{h}]$} & {$\left[\mathrm{l}_{\mathrm{H} 2} / \mathrm{l}_{\mathrm{wax}}\right]$} & [h] \\
\hline HFB-1 & 140 & 280 & 0.5 & 760 & 35.5 \\
\hline HFB-2 & 140 & 300 & 0.5 & 760 & 41.5 \\
\hline HFB-3 & 140 & 320 & 0.5 & 760 & 28 \\
\hline HFB-4 & 140 & 340 & 0.5 & 760 & 39 \\
\hline HFB-5 & 100 & 300 & 0.5 & 760 & 24 \\
\hline
\end{tabular}

Wax B was tested regarding the requirements for "Paraffin (synthetic)" defined by the American FDA. The thresholds regarding congealing point and oil content were fulfilled by obtaining a wax with a suitable boiling range. The absorption measurement in decalin could not be performed due to the high melting range of Wax $\mathrm{B}$. To perform the absorption measurement the hydrocarbons would have to be heated to over $140{ }^{\circ} \mathrm{C}$. Several absorption measurements at this temperature level with different waxes were performed. The absorption at $290 \mathrm{~nm}$ of the tested waxes increased with time. Thus, it is assumed that oxidation falsified the results of this method at elevated temperatures. Based on this finding it was decided to evaluate the waxes regarding ar omatic impurities with a GC/MS method.

To gain insights regarding the PAH content in the paraffin waxes a GC MS analysis was performed. The method applied to analyze the PAH content in paraffin wax is based on DIN EN 16134. The lower limit of determination (LoD) of the method was $0.5 \mu \mathrm{g}$ per $\mathrm{kg}$ wax. The results of the analysis are shown in Table 7. The raw Wax A and Wax B were compared to hydrofined products HFA 7 and HFB 2 , respectively. The highest single substance concentration in Wax A was analyzed for pyrene, which could be reduced to $2.5 \mu \mathrm{g} / \mathrm{kg}$ through hydrofining. Wax A showed an increased concentration of benz(a)anthracene, triphenylene and chrysene after hydrofining. In Wax B Naphthalene showed the highest concentration, which could be reduced by two thirds by hydrofining. Most of the PAH analyzed in Wax B could be reduced to levels below LoD.

\section{Conclusion}

Renewable raw FT wax was produced via gasification of ligno cellulosic feedstock, LTFT and hydrofining. A medium melt and a high melt wax were obtained from the raw FT syncrude by distil lation. The whitish/yellowish raw medium melt wax had a Saybolt Color of +15 . The yellowish/brownish high melt wax fraction had a Saybolt Color below 16. Both wax fractions were hydrofined using a commercial sulfide $\mathrm{Ni} / \mathrm{Mo}-\mathrm{Al}_{2} \mathrm{O}_{3}$ catalyst in a heated and pres surized trickle bed fixed bed reactor.

The hydrofining of the medium melt FT wax was performed at $260-280^{\circ} \mathrm{C}$ and $35-140$ bar. The hydrofining of the medium melt wax, with the aim of Saybold color +30 and compliance to the $\mathrm{Ph}$. Eur. was successfully performed at mild process conditions. A product quality decline, indicated by a rising hot acid grade, was observed at 35 bar. The presented work showed that FT wax,

Table 6

Physical- and chemical properties of the hydrofined medium-melt waxes.

\begin{tabular}{|c|c|c|c|c|c|c|c|c|}
\hline Parameter & Unit & Wax A Feed & HFA-1 & HFA-2 & HFA-3 & HFA-4 & HFA-5 & HFA-6 \\
\hline Cumulative experiment duration & [h] & 0 & 28.5 & 53 & 82 & 120 & 157 & 187 \\
\hline Saybolt Color & {$[-]$} & +15 & +30 & +30 & +30 & +30 & +30 & +30 \\
\hline Hot acid test & {$[-]$} & $>3$ & 1 & 1 & 1 & 1.5 & 2 & 1 \\
\hline Congealing point & {$\left[{ }^{\circ} \mathrm{C}\right]$} & 58 & 58 & 58 & 59 & 59 & 58 & 59 \\
\hline Needle penetration & {$\left[10^{1} \mathrm{~mm}\right]$} & 52 & 51 & 51 & 50 & 51 & 49 & 51 \\
\hline Oil content & [wt.\%] & 5.84 & 6.13 & 5.64 & 5.61 & 5.39 & 5.30 & 5.20 \\
\hline SIMDIST > 5 wt\% & {$\left[{ }^{\circ} \mathrm{C}\right]$} & 355 & 353 & 354 & 354 & 355 & 355 & 351 \\
\hline SIMDIST > 95 wt\% & {$\left[{ }^{\circ} \mathrm{C}\right]$} & 515 & 513 & 514 & 512 & 512 & 513 & 514 \\
\hline
\end{tabular}
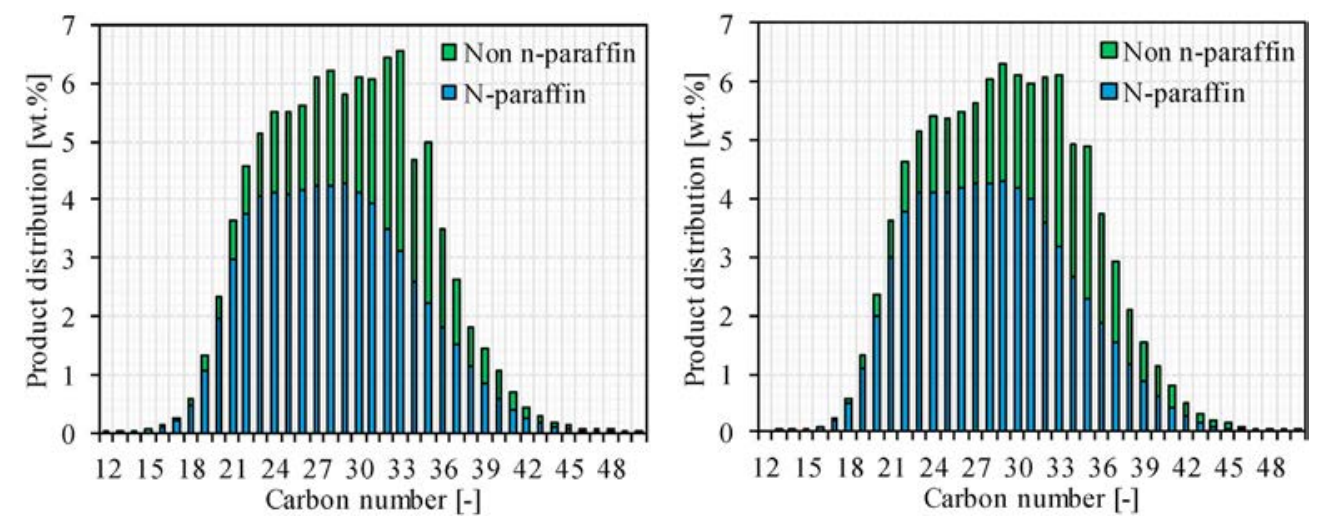

Fig. 9. GC analysis regarding n-paraffin content after hydrofining (left: HFA-2, right HFA-6). 


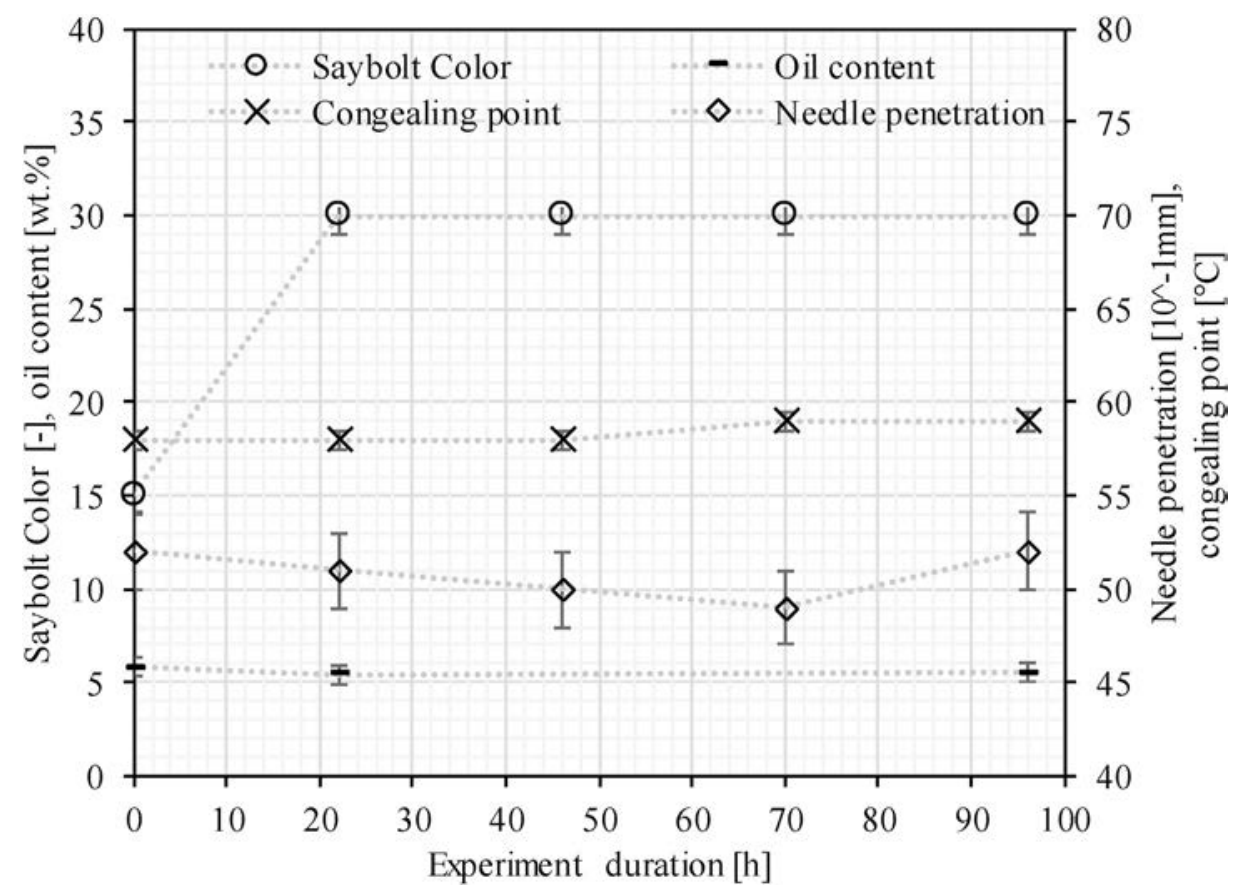

Fig. 10. Results of long-term hydrofining test run with Wax A at $100 \mathrm{bar}, 280{ }^{\circ} \mathrm{C}, 750 l_{\mathrm{H}_{2}} \boldsymbol{\#}_{\text {Wax }}$ and $0.5 \mathrm{~h}{ }^{1 .}$
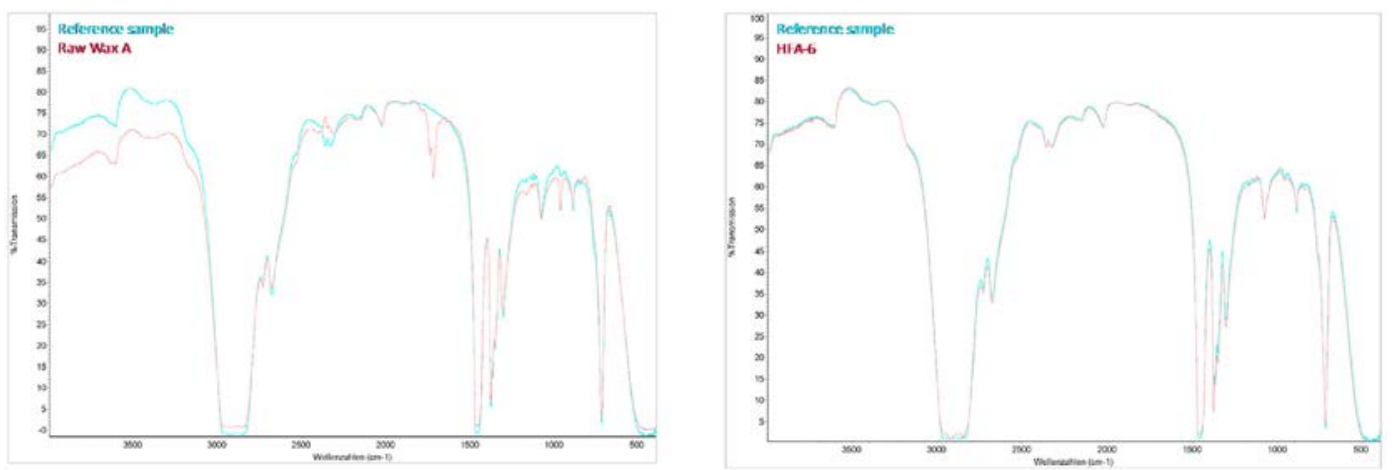

Fig. 11. IR Spectrum of a commercial medium melt wax (full compliance with Ph. Eur.) and the raw Wax A (left) and HFA-6 (right).

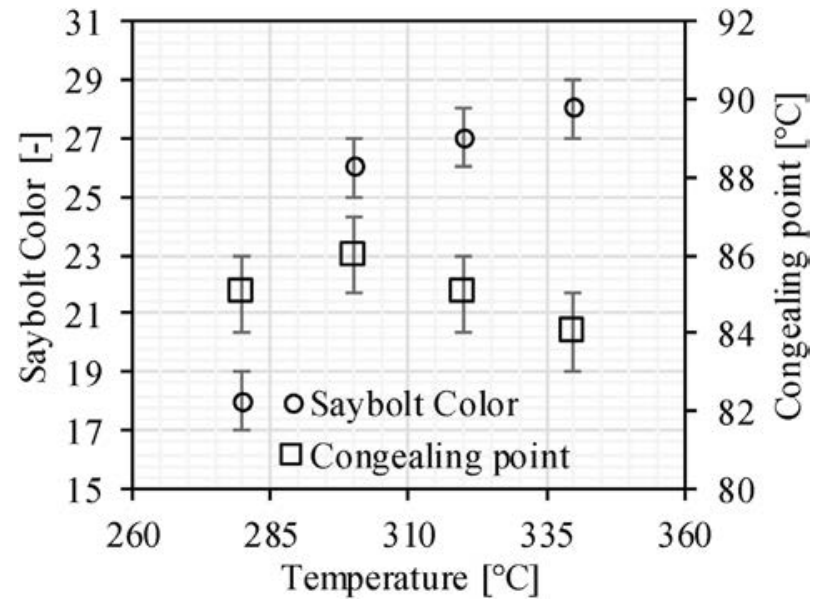

Fig. 12. Wax B: Saybolt Color and congealing point as a function of temperature at constant pressure (140 bar), SV $\left(0.5 \mathrm{~h}^{1}\right)$ and $\mathrm{H}_{2}$ to wax ratio $\left(760 l_{\mathrm{H}_{2}}=l_{\text {wax }}\right.$ ).

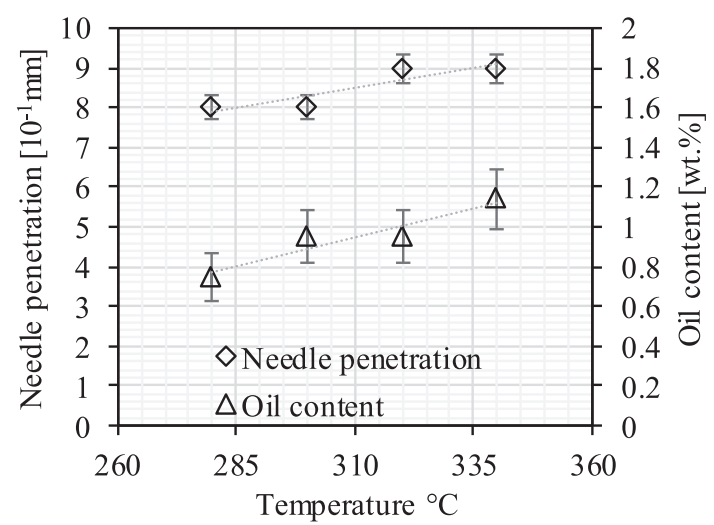

Fig. 13. Wax B: Needle penetration and oil content as a function of temperature at constant pressure (140 bar), $\mathrm{SV}\left(0.5 \mathrm{~h}^{1}\right)$ and $\mathrm{H}_{2}$ to wax ratio $\left(760 l_{\mathrm{H}_{2}} \#_{\text {wax }}\right)$. 


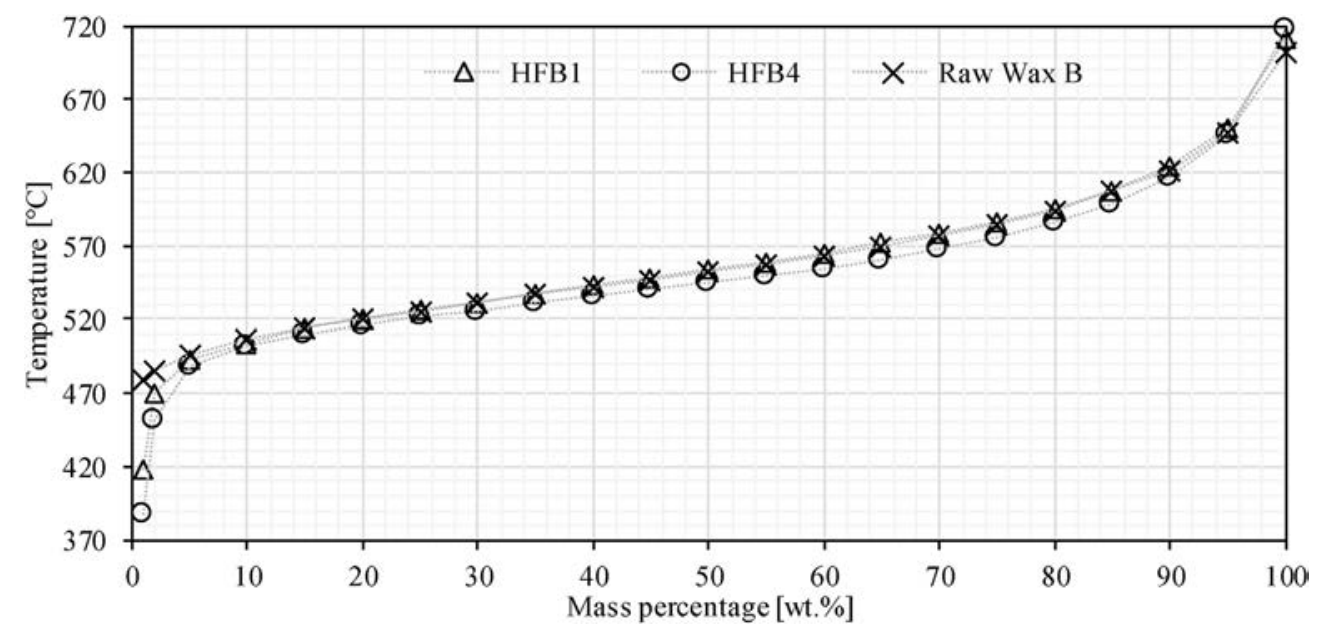

Fig. 14. SIMdist analysis of raw Wax B compared to HFB-1 (140 bar/280 $\left.{ }^{\circ} \mathrm{C} / 0.5 \mathrm{~h}^{1}\right)$ and HFB-4 $\left(140 \mathrm{bar} / 340^{\circ} \mathrm{C} / 0.5 \mathrm{~h}{ }^{1}\right)$.

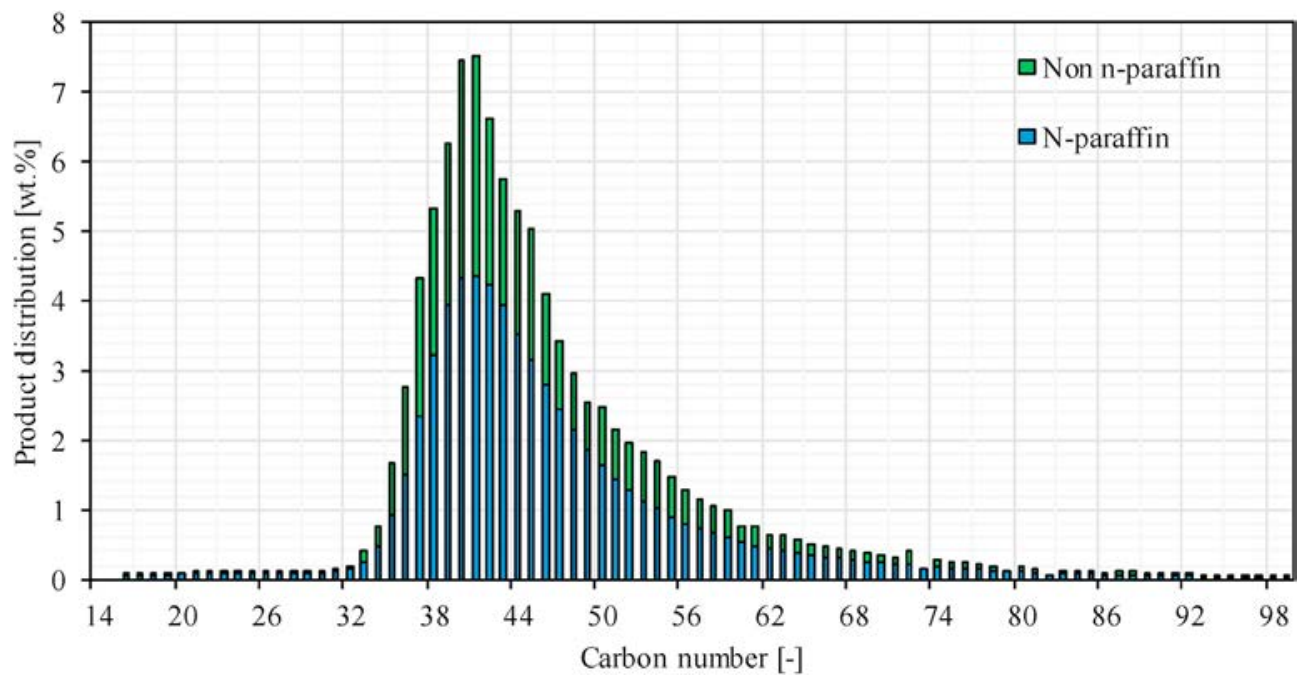

Fig. 15. Carbon number distribution and n-paraffin content of HFB-4.

obtained from cobalt based LTFT and refined at 60 bar and $280{ }^{\circ} \mathrm{C}$ using a commercial sulfide NiMo catalysis, could match the criteria defined by the Ph. Eur. for "Paraffinum solidum". Thus, it might be concluded that due to the high n paraffin share of raw wax pro duced by cobalt based LTFT, it can be refined to pharmaceutical grade paraffin at mild conditions using a commercially available catalyst. Note that synthetic paraffin produced via FTS and gasifi cation (any feedstock) is not mentioned explicitly to be conform with the Ph. Eur. monograph "Paraffinum solidum". At this point, the authors would like to refer to the monograph "Paraffinum syntheticum" (European Directorate for the Quality of Medicines (EDQM), 2020) which is, currently under elaboration. Further evaluations regarding the compliance of FT paraffin to the accord ing Ph. Eur. monograph will be necessary upon release.

The hydrofining of high melt FT wax was performed at $280-340^{\circ} \mathrm{C}$ and $100-140$ bar. By increasing the temperature from $280{ }^{\circ} \mathrm{C}$ to $340{ }^{\circ} \mathrm{C}$ at 140 bar the Saybolt color could be increased from +18 to +28 . However, at $340{ }^{\circ} \mathrm{C}$ the oil content increased by $52 \%$ to $1.14 \mathrm{wt} \%$, compared to the associated $280^{\circ} \mathrm{C}$ experiment and thus indicating a decrease in high melt wax yield. Depending on the subsequent wax application the trade off between yield and color quality must be further considered from an economic point of view. Furthermore, it was shown that Wax B could match the criteria for oil content and congealing point defined by the Amer ican FDA for "synthetic paraffin for indirect food additives". Due to the high melting range of Wax $B$ the absorption measurement at $290 \mathrm{~nm}$, which is demanded by FDA, could not be performed at $88^{\circ} \mathrm{C}$. To tackle this issue, an additional high melt cut needs to be implemented in the distillation process.

\section{CRediT authorship contribution statement}

Hannes Gruber: Conceptualization, Investigation, Writing re view \& editing, Funding acquisition. Lukas Lindner: Investigation, Writing original draft. Stefan Arlt: Writing review \& editing. Alexander Reichhold: Conceptualization, Supervision. Reinhard Rauch: Funding acquisition. Gerald Weber: Conceptualization, Resources, Writing review \& editing, Supervision, Project administration, Funding acquisition. Jürgen Trimbach: Conceptu alization, Resources, Supervision. Hermann Hofbauer: Supervision. 
Table 7

Results of the GC-MS for FT waxes regarding PAH content.

\begin{tabular}{|c|c|c|c|c|}
\hline Compound & Raw Wax A & HFA-7 & Raw Wax B & HFB-2 \\
\hline & {$[\mu \mathrm{g} / \mathrm{kg}]$} & {$[\mu \mathrm{g} / \mathrm{kg}]$} & {$[\mu \mathrm{g} / \mathrm{kg}]$} & {$[\mu \mathrm{g} / \mathrm{kg}]$} \\
\hline Naphthalene & 7 & 3.9 & 6 & 1.7 \\
\hline Acenaphthylene & 0.7 & $<$ LoD & 0.6 & $<$ LoD \\
\hline Acenaphthene & 1.8 & $<$ LoD & 0.9 & $<$ LoD \\
\hline Fluorene & 4.1 & 0.9 & 2.7 & 0.7 \\
\hline Phenanthrene & 5.6 & 2.7 & 4.1 & 1.3 \\
\hline Anthracene & 0.7 & $<$ LoD & 1.1 & $<$ LoD \\
\hline Fluoranthene & 10.1 & 1 & 2.3 & $<$ LoD \\
\hline Pyrene & 14.6 & 2.5 & $<$ LoD & 0.6 \\
\hline Benzo (c)fluorene & 2.3 & 0.8 & $<$ LoD & $<$ LoD \\
\hline Benzo [b]naphtho[1,2-d]thiophene & $<$ LoD & 2.4 & $<$ LoD & $<$ LoD \\
\hline Benzo [ghi]fluoranthene & 0.6 & $<$ LoD & $<$ LoD & $<$ LoD \\
\hline Benzo [c]phenanthrene & $<$ LoD & $<$ LoD & $<$ LoD & $<$ LoD \\
\hline Cyclopenta [cd]pyrene & 1.3 & $<$ LoD & $<$ LoD & $<$ LoD \\
\hline Benz (a)anthracene & 1.3 & 1.5 & $<$ LoD & $<$ LoD \\
\hline Triphenylene & 1 & 2.5 & $<$ LoD & $<$ LoD \\
\hline Chrysene & 1.8 & 3.1 & $<$ LoD & $<$ LoD \\
\hline 5-Methylchrysene & $<$ LoD & $<$ LoD & $<$ LoD & $<$ LoD \\
\hline Benzo [b]fluoranthene & 2.6 & $<$ LoD & $<$ LoD & $<$ LoD \\
\hline Benzo [k]fluoranthene & 1.1 & $<$ LoD & $<$ LoD & $<$ LoD \\
\hline Benzo [j]fluoranthene & 1.2 & $<$ LoD & $<$ LoD & $<$ LoD \\
\hline Benzo (e)pyrene & 1.6 & $<$ LoD & $<$ LoD & $<$ LoD \\
\hline Benzo (a)pyrene & $<$ LoD & $<$ LoD & $<$ LoD & $<$ LoD \\
\hline Perylene & $<$ LoD & $<$ LoD & $<$ LoD & $<$ LoD \\
\hline Indeno[1,2,3-cd]pyrene & 0.7 & $<$ LoD & $<$ LoD & $<$ LoD \\
\hline Benzo(ghi)perylene & 1.7 & 0.5 & 0.5 & $<$ LoD \\
\hline Anthanthrene & $<$ LoD & $<$ LoD & $<$ LoD & $<$ LoD \\
\hline Dibenz(a,j)anthracene & $<$ LoD & $<$ LoD & $<$ LoD & $<$ LoD \\
\hline Dibenz(a,h)anthracene & 0.6 & $<$ LoD & $<$ LoD & $<$ LoD \\
\hline Coronene & 2.1 & 1.5 & 0.6 & 2.1 \\
\hline Dibenzo [a,e]pyrene & $<$ LoD & $<$ LoD & $<$ LoD & $<$ LoD \\
\hline Dibenzo [a,l]pyrene & $<$ LoD & $<$ LoD & $<$ LoD & $<$ LoD \\
\hline Dibenzo [a,h]pyrene & $<$ LoD & $<$ LoD & 2 & 0.6 \\
\hline Dibenzo [a,i]pyrene & $<$ LoD & $<$ LoD & 0.8 & $<$ LoD \\
\hline
\end{tabular}

\section{Declaration of competing interest}

The authors declare that they have no known competing financial interests or personal relationships that could have appeared to influence the work reported in this paper.

\section{Acknowledgment}

"The project team has received funding from the COMET pro gram managed by the Austrian Research Promotion Agency under grant number 844605 . The program is co financed by the Republic of Austria and the Federal Provinces of Burgenland, Lower Austria and Styria. Co funding from the industry partners H\&R GmbH \& Co. KGaA and Bilfinger Bohr und Rohrtechnik $\mathrm{GmbH}$, should be notably acknowledged."

\section{References}

Agrawal, S.L., Mandot, S., Bandyopadhyay, S., Mukhopadhyay, R., Deuri, A.S., 2005. The effect of waxes on rubber vulcanisates. Prog. Rubber Plast. Recycl. Technol. 21, 139 153. https://doi.org/10.1177/147776060502100204.

Bahri, S., Venezia, A.M., Upadhyayula, S., 2019. Utilization of greenhouse gas carbon dioxide for cleaner Fischer-Tropsch diesel production. J. Clean. Prod. 228, 1013 1024. https://doi.org/10.1016/j.jclepro.2019.04.310.

Boerrigter, H., Den Uil, H., Calis, H.-P., 2002. Green Diesel from Biomass via FischerTropsch Synthesis: New Insights in Gas Cleaning and Process Design. October 113.

Bolder, F.H.A., 2007. Fischer-Tropsch wax hydrogenation over a sulfided nickelmolybdenum catalyst. Energy Fuel. 21, 1396 1399. https://doi.org/10.1021/ ef060614a.

Bolhar-Nordenkampf, M., Hofbauer, H., 2004. GASIFICATION DEMONSTRATION PLANTS IN AUSTRIA. IV, vol. 2. Internaional Slovak Biomass forum, Bratislava, pp. 227 230. https://doi.org/10.13140/2.1.4084.1280.

Dalai, A.K., Davis, B.H., 2008. Fischer Tropsch synthesis: a review of water effects on the performances of unsupported and supported Co catalysts. Appl. Catal.
Gen. 348, 1 15. https://doi.org/10.1016/j.apcata.2008.06.021.

de Klerk, A., Furimsky, E., 2010a. Upgrading of fischer tropsch waxes. In: Catalysis in the Refining of Fischer-Tropsch Syncrude. RSC Catalysis Series, pp. 165182

de Klerk, A., Furimsky, E., 2010b. Catalysis in the upgrading of fischer tropsch syncrude. In: Catalysis in the Refining of Fischer Tropsch Syncrude. The Royal Society of Chemistry, pp. 40164.

de Klerk, A., Maitlis, P.M., 2013. Chapter 4 - what can we do with fischer tropsch products? In: Maitlis, P.M., Klerk, A. de (Eds.), Greener Fischer-Tropsch Processes for Fuels and Feedstocks. Wiley-VCH Verlag \& Co. KGaA, pp. 81106.

Deutsche Gesellschaft für Fettwissenschaften, 1975. DGF-einheitsmethoden. Wachse und Wachsprodukte, Stuttagrt. Abteilung M.

Dry, M.E., Steynberg, A.P., 2004. Commercial FT process applications. In: Steynberg, A., Dry, M.E. (Eds.), Fischer-Tropsch Technology. Elsevier Science, pp. 406 481. https://doi.org/10.1016/S0167-2991(04)80462-2.

Eilers, H., 2018. Flexibler Betrieb der Fischer-Tropsch Synthese - Katalysator- und Reaktorverhalten mit Co in der 3-Phasen-Blasensaule - PhD Thesis KIT.

European Directorate for the Quality of Medicines (Edqm), 2020. Online knowledge database - monograph paraffinum syntheticum [WWW Document]. https:// extranet.edqm.eu/4DLink1/4DCGI/Web_View/mono/2263. accessed 5.2.19.

Gruber, H., Groß, P., Rauch, R., Reichhold, A., Zweiler, R., Aichernig, C., Müller, S., Ataimisch, N., Hofbauer, H., 2019. Fischer-Tropsch products from biomassderived syngas and renewable hydrogen. Biomass Convers. Biorefinery. https://doi.org/10.1007/s13399-019-00459-5. https://link.springer.com/article/ 10.1007/s13399-019-00459-5\#citeas.

Kalish, J.P., Ramalingam, S., Bao, H., Hall, D., Wamuo, O., Hsu, S.L., Paul, C.W., Eodice, A., Low, Y.G., 2015. An analysis of the role of wax in hot melt adhesives. Int. J. Adhesion Adhes. 60, 63 68. https://doi.org/10.1016/ j.ijadhadh.2015.03.008.

Krendlinger, E., Wolfmeier, U., Schmidt, H., Heinrichs, F., Michalczyk, G., Payer, W., Dietsche, W., Boehlke, K., Hohner, G., Wildgruber, J., 2015. Waxes. In: In Ullmann's Encyclopedia of Industrial Chemistry. Wiley-VCH Verlag GmbH \& Co. KGaA. https://doi.org/10.1002/14356007.a28_103.pub2.

Leng, Z., Yu, H., Zhang, Z., Tan, Z., 2017. Optimizing the mixing procedure of warm asphalt rubber with wax-based additives through mechanism investigation and performance characterization. Construct. Build. Mater. 144, 291 299. https:// doi.org/10.1016/j.conbuildmat.2017.03.208.

Masson-Delmotte, V., Zhai, P., Portner, H.-O., Roberts, D., Skea, J., Shukla, P.R. Pirani, A., Moufouma-Okia, W., Péan, C., Pidcock, R., Connors, S., Matthews, J.B.R., Chen, Y., Zhou, X., Gomis, M.I., Lonnoy, E., Maycock, T., Tignor, M., 2018. IPPC - summary for policymakers. In: Global Warming of $1.5^{\circ} \mathrm{C}$. 
An IPCC Special Report on the Impacts of Global Warming of $1.5^{\circ} \mathrm{C}$ above Preindustrial Levels and Related Global Greenhouse Gas Emission Pathways, in the Context of Strengthening the Global Resp. World Meteorological Organization, Geneva, Switzerland.

Oecd/Iea, 2018. The Future of Petrochemicals -Towards More Sustainable Plastics and Fertilisers.

Paul, C.W., 2003. Hot-melt adhesives. MRS Bull. 28, 440444

Rauch, R., Kiennemann, A., Sauciuc, A., 2013. Chapter 12 - fischer-tropsch synthesis to biofuels (BtL process). In: Triantafyllidis, K.S., Lappas, A.A., Stocker, M. (Eds.), The Role of Catalysis for the Sustainable Production of Bio-Fuels and BioChemicals. Elsevier B.V., pp. 397 443. https://doi.org/10.1016/B978-0-44456330-9.00012-7

Ripfel-Nitsche, K., 2017. Liquid fuel production from biomass gasification product gas of the biomass gasifier at güssing/Austria catalyst characterisation. PhD
Thesis. In: Desing, Construction and Operation of a Fischer Tropsch Pilot Plant. TU Wien.

Speight, J.G., 2011. Chapter 3 - hydrocarbons from petroleum. In: Speight, J.G. (Ed.) Handbook of Industrial Hydrocarbon Processes. Gulf Professional Publishing, Boston, pp. 85 126. https://doi.org/10.1016/B978-0-7506-8632-7.10003-9.

Steynberg, A.P., 2004. Introduction to fischer-tropsch technology. In: Steynberg, A., Dry, M.E. (Eds.), Fischer-Tropsch Technology. Elsevier Science, pp. 163.

United Nations, 2019. The Katowice Climate Package: Making the Paris Agreement Work for All ([WWW Document]).

Wen, Y., Wang, Y., Zhao, K., Chong, D., Huang, W., Hao, G., Mo, S., 2018. The engineering, economic , and environmental performance of terminal blend rubberized asphalt binders with wax-based warm mix additives. J. Clean. Prod. 184, 985 1001. https://doi.org/10.1016/j.jclepro.2018.03.011. 
Karlsruher Institut für Technologie

\section{Repository KITopen}

Dies ist ein Postprint/begutachtetes Manuskript.

\section{Empfohlene Zitierung:}

Gruber, H.; Lindner, L.; Arlt, S.; Reichhold, A.; Rauch, R.; Weber, G.; Trimbach, J.; Hofbauer, $\mathrm{H}$.

A novel production route and process optimization of biomass-derived paraffin wax for pharmaceutical application.

2020. Journal of cleaner production, 275.

doi: $\underline{10.5445 / I R / 1000123972}$

Zitierung der Originalveröffentlichung:

Gruber, H.; Lindner, L.; Arlt, S.; Reichhold, A.; Rauch, R.; Weber, G.; Trimbach, J.; Hofbauer, $\mathrm{H}$.

A novel production route and process optimization of biomass-derived paraffin wax for pharmaceutical application.

2020. Journal of cleaner production, 275, Article no: 124135.

doi:10.1016/j.jclepro.2020.124135

Lizenzinformationen: $\underline{\text { C B BY-NC-ND } 4.0}$ 